\title{
Surgical treatment for cervical subluxation caused by trauma: A report case and literature review
}

\author{
Diego Quillo Olvera ${ }^{1}$, Javier Quillo Olvera ${ }^{2}$, Javier Quillo Resendiz ${ }^{2}$ and Francisco Velazquez Garcia ${ }^{2}$ \\ ${ }^{1}$ Resident of fourth year of Neurosurgery, Institute of Security and Social Services of Workers of the State (ISSSTE), Hospital Valentín Gómez Farías, Zapopan, \\ Jalisco, Mexico \\ ${ }^{2}$ Neurosurgery and Spine Surgery, The Brain and Spine Care Center, Minimally Invasive Spine Surgery Center, Santiago de Querétaro, Querétaro, Mexico
}

\begin{abstract}
A 62-year-old man falls and presenting cervical trauma, hyperflexion of the neck and sudden quadriparesis $2 / 5$ and cervical pain. He was taken to the emergency department within the first $8 \mathrm{hrs}$ after the fall where the cervicothoracic CT scan and MRI done and revealed C6-C7 bilateral facet joint dislocation and anterior translation of $\mathrm{C} 6$ over $\mathrm{C} 7$. The patient underwent surgery to perform laminectomy $\mathrm{C} 4-\mathrm{C} 5-\mathrm{C} 6$, partial facet joint resection $\mathrm{C} 6$ and posterior lateral mass fixation $\mathrm{C} 4-$ $\mathrm{C} 5$ and transfacet T1-T2 screws obtaining a reduction of subluxation of $\mathrm{C} 6$, improving of the alignment in saggital plane and the neurological deficit of the 4 limbs. In this review we present physiopathological, radiological aspects and surgical options dependent on the involvement of the anatomical elements of the cervical spine.
\end{abstract}

\section{Introduction}

Car accidents, firearm injuries and sports activities are the most common cause of cervical spine injury $[1,2]$. Sub-axial cervical spine, defined as $\mathrm{C} 3$ to $\mathrm{C} 7$ is vulnerable to traumatic injury, $65 \%$ of the fractures and more $\tan 75 \%$ of all dislocations in spine most often C5-C7 [3]. These cervical spine injuries may associated with a severe permanent disability caused by spinal cord injury. Mortality rate is approximately $6 \%$, incomplete quadriplegia was found in $40 \%$ and compelte quadriplegia in $16 \%$ [4].

In accordance with Sameer et al. Hyperflexion is the most frequent type of injury vector encountered in patients with vertebral trauma, the injury spectrum includes compressive hyperflexion, vertical compression and distractive hyperflexion [5].

The goals of surgery are realignment and cervical balance, decompression of the neural elements and instrumented stabilization with a solid construct. We present a case of male 62 years old with subluxation of c6-c7 cused by trauma and and his surgical treatment.

\section{Case report}

A 62-year-old man falls presenting a hyperflexion of the neck and sudden quadriparesis. He was taken to the emergency department within the first $8 \mathrm{hrs}$ after the fall where the cervicothoracic CT scan and MRI done and revealed $\mathrm{C} 6-\mathrm{C} 7$ bilateral facet joint dislocation and anterior translation of C6 over C7 (Figure 1). The patient underwent surgery to perform laminectomy C4-C5-C6, partial facet joint resection C6 and posterior C4-C5 lateral mass fixation, T1-T2 transfacet screws obtaining a reduction of subluxation of $\mathrm{C} 6$ improving of the alignment in saggital plane (Figure 2) and neurological deficit of the 4 limbs (Figure 3).

\section{Discussion}

Allen-Ferguson classify in 6 types the cervical injuries: compressionflexion, vertical compression, distraction-flexion, compressionextension, distraction-extension, and lateral flexion; however it is no longer used. The AO classification of fractures of subaxial cervical spine consists of three types A: compression; B: distraction; C: rotation, while the groups and subgroups define the morphological parameters [7].

Once we recognize the affected mechanism we can understand the injured anatomical site and decide a surgical approach. There are hyperextension injury and hyperflexion injury with compression and distractive mechanism. When there is hyperextension movement extension vector with centre of rotation is behind the anterior column, resulting in axial loading force applied to the posterior column, resulting in compressive failure of the posterior column. With increasing magnitude of force, anterior column distraction and tensile failure might occur. In the hyperflexion movement flexion vector with centre of rotation anterior to the anterior column, resulting in posterior column distraction with progressive tensile failure of the posterior column. In sagital plane of the tomography exist some lines that keeps the alignment and we can evaluate, those are spinolaminar line, interspinous line, anterior and posterior vertebral lines, but posterior vertebral lines is the most reliable and accurate indicator of the antereroposterior alignament; the spinolaminar line is very useful in differentiating between hyperextension and hyperflexion injury because this line is not interrupted at the level of anterolisthesis in hyperextension injury [5].

Bilateral facet dislocation is the most severe injury of the flexiondistraction spectrum, causing complete disruption of facet joint capsule

${ }^{\star}$ Correspondence to: Diego Quillo Olvera, Resident of fourth year of Neurosurgery, Institute of Security and Social Services of Workers of the State (ISSSTE), Hospital Valentín Gómez Farías, Zapopan, Jalisco, Mexico, E-mail: drquilloolvera86@gmail.com

Key words: Cervical subluxation; bilateral facet joint dislocation; cervical trauma cervical injury; cervical stabilization.

Received: February 06, 2019; Accepted: February 18, 2019; Published: February 21, 2019 


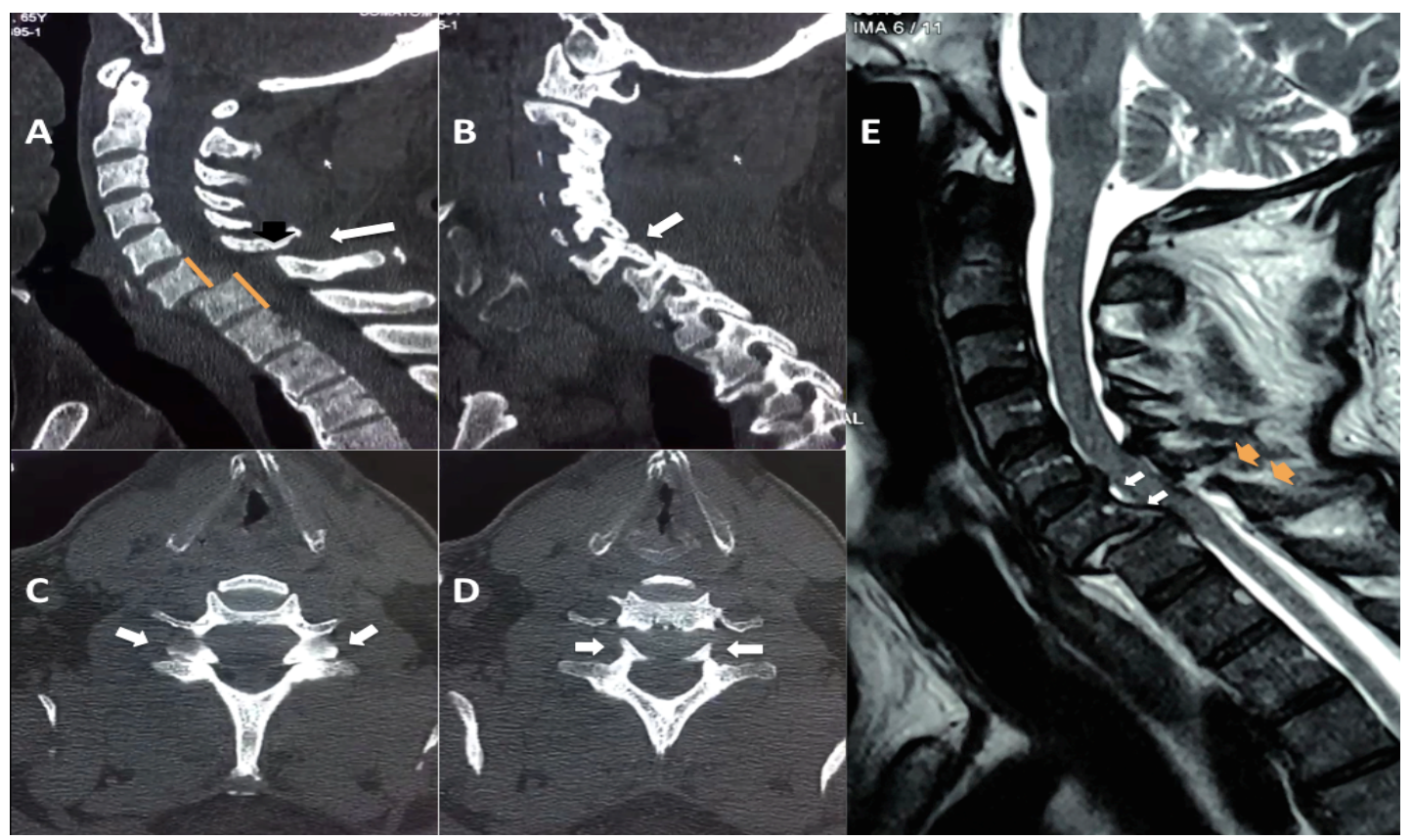

Figure 1. Pre-operatory image: A-B sagittal CT of cervical spine, A. orange line show the anterior translation of $50 \% \mathrm{C} 6$ over C7, black arrow mark the dislocation of the spinolaminar line, white arrow points the increase in the distance of the interspinous space secondary to the rupture of the interspinous ligament. B.white arrow mark facet joint dislocation C6-C7. C-D Axial CT of cervical spine image C. white arrow mark the sign the reverse "hamburger bun secundary to the facet joint dislocation C6-C7. D. "headphones sign" pointed by white arrow are the uncinate process of $\mathrm{C} 6$ vertebral body. E. Sagittal MRI of cervical spine T2 weighted, white arrow poins whole posterior longitudinal ligament with the anterior translation of the C6 vertebral body and orage narrow show disruption of interespinous ligament width more than $2 \mathrm{~mm}$ and loss of the alignment of the posterior elements

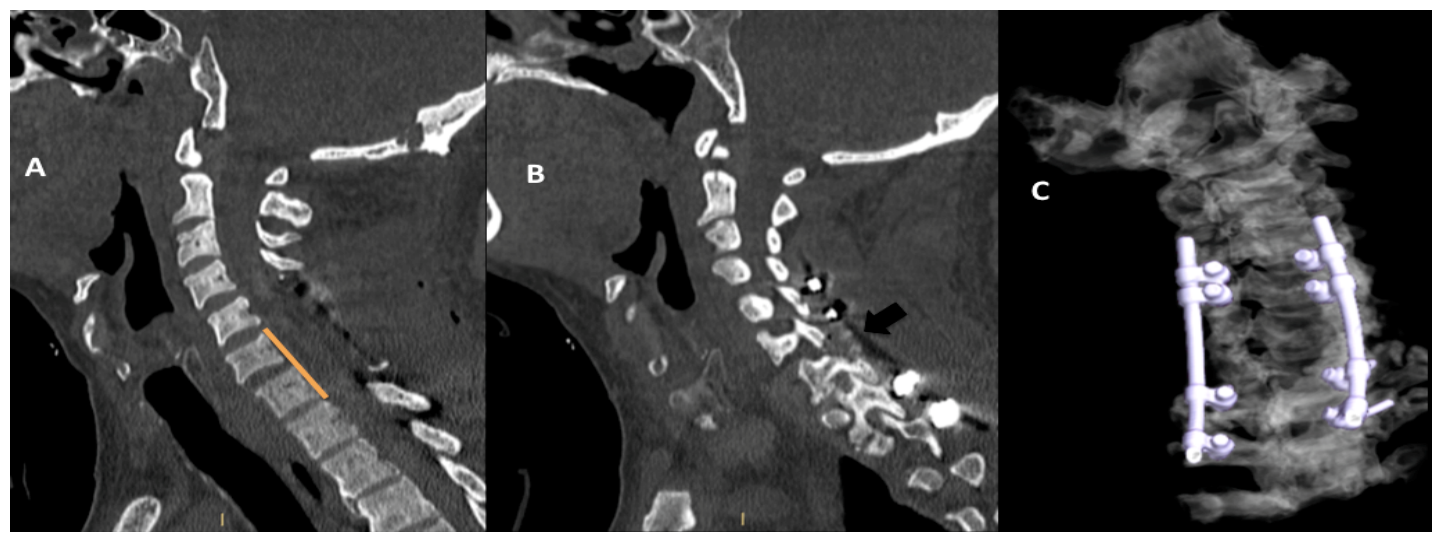

Figure 2. Postop sagittal CT of cervical spine A. Aligment improvement C6-C7 in orange line with posterior decompresion laminectomy C4-C6. B. Black arrow show partial facet joint resection C6. C. 3D CT cervical reconstruction of the construct C4-C5 lateral mass fixation, T1-T2 transfacet screws

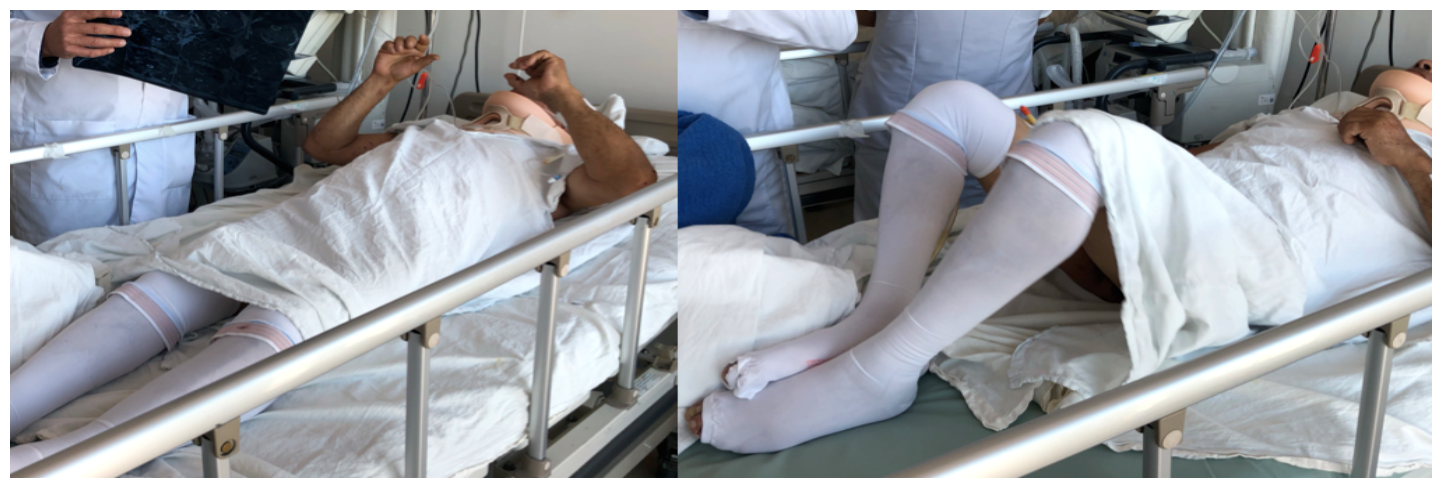

Figure 3. Postop Improvement of neurological injury, mobilization arms and legs 
and interspinous ligament, ligament flavum,supraspinous ligament in all cases. The posterior longitudinal ligament disruption is also described in $40-100 \%$ of cases with bilateral facet joint dislocation. Traumatic disc herniation with posterior annulus disruption is described in $56 \%$ of unilateral and $82.5 \%$ of bilateral facet dislocations [8].

The axial CT are not very useful to diagnose facet joint dislocation, there are several signs of diagnosing facet joint dislocation including the naked facet sign, the reverse "hamburger bun" and the "headphones sign" Pre-operative cervical MRI needs for the treatment decision in patients with unilateral or bilateral facet joint dislocation and look for intervertebral disc disruption [9-11].

Some messurements can be taken for radiographic assessment included global and regional sagittal balance parameters, C2-C7 angle (inferior endplate lines), C7 slope, sagittal vertical axis (SVA) of C2, C7 and $\mathrm{S} 1$ but in the case of trauma the important lines as spinolaminar line, interspinous line, anterior and posterior vertebral lines are important for the selection of the approach [8].

Interspinous, interlaminar and interpedicular distances, and also facet joint width are abnormal if there more than $2 \mathrm{~mm}$ of difference between the adjacent segments. Interlaminar distance is accurate than interspinous distance for diagnosing hyperflexion injury [6].

\section{Steroids in spine cord injury}

High dose methylprednisolone $(30 \mathrm{mg} / \mathrm{kg}$ bolus followed by a 5.4 $\mathrm{mg} / \mathrm{kg} / \mathrm{h}$ infusion) has been recommended for patients before $8 \mathrm{hrs}$ from the injury, they presents a modest neuroprotective effect administered for 24 to $48 \mathrm{hrs}$ based on recommendations from the NASCIS II and III trials, however some studies shows the steroids did not a significant Benefit $[13,14]$.

\section{Reduction with traction}

Reduction of dislocations and restoration of normal alignment also reduces the abnormal stretch of the ligaments and muscles, thereby reducing the pain can be achieved with the use of Gardner-wells skull tongs. The procedure is performed with the patient awake in the intensive care unit, the axial traction starts with the neck in $20^{\circ}-30^{\circ}$ flexion, $5 \mathrm{~kg}$ applied an added until 12 to $30 \mathrm{kgs}$ from $10 \mathrm{~min}$ to 3 hours to achieve a reduction, this procedure is successful in up $98 \%$ in patients whom before $8 \mathrm{hrs}$ of the injury, when added wight to the traction this should be $2 \mathrm{~kg}$ every 10 minutes until facet joints get unlocked and confirm with X-ray [14].

\section{Surgical treatment}

Skeletal and soft tissue damage are often associated with cervical spine injury, posterior facet fractures, ligamentous avulsion, and fibrous annulus rupture, lead to instability of the spine and increase difficulty in cervical reduction. Surgery may be performed via the anterior, posterior, or double routes. Because of the instability associated with dislocations, we need achieve adequate reduction, stabilization and spinal cord decompression $[4,8,15]$. For the previse and correction of the for cervical spine injuries due to trauma that, although they do not cause a fracture at that time, will cause a future deformity in the cervical spine, such as the posterior ligament complex, we can use surgical approaches such as those described by Schwab, et al, published in 2012 in 7 grades for the surgery of cervical osteotomy, includes gradel partial facet joint resection, grade 2 complete facet joint/Ponte osteotomy, grade 3 partial or complete corpectomy, grade 4 complete uncovertebral joint resection to transverse foramen, grade 5 opening wedge osteotomy, grade 6 closing wedge osteotomy and grade 7 complete vertebral column resection; in this case we use the grade 1 cervical osteotomy at C6 level, to unlock facet join dislocation [16].

The hyperflexion distraction with the injury of the facet joint capsule and interspinous ligament, ligament flavum, supraspinous ligament can results in delayed mechanical instability and should be stabilised and fused. The hyperextension distraction with the injury of the anterior longituinal ligament and intervertebral disc, mandates anterior surgery with stabilisation. Some authors recomended the length of the posteiror fix depends of the force vectors involved, the significant translation and rotation vectors both require long segment stabilisation; two motion segments above and below injury [5].

Zaveri commented on his revision the surgical choice depending on the mechanism of injury already described by Allen in 1982 with 6 types of injuries; vertical compresion, compressive flexion,distractive flexion, compressive extension,distractive extension and lateral flexion injuries; depending on the presence of kyphosis, alignment, burst fracture of the vertebral body, retrolisthesis, unilateral or bilateral subluxation of the facet joint, compression of the medullary cord or posterior longitudinal ligament, intervertebral disc, posterior bony structures and the posterior ligaments, and especially neurological injury, treatment options may be external immobilization for 8-12 weeks, anterior corpectomy, discectomy and posterior fixation with or without posterior decompression $[4,6]$.

\section{Conclusion}

In this case the patient presented distractive flexion injury. In the literature the posterior approach is the most used by surgeos in this kind of injuries. An adequate realignment and improvement of the neurological status was obtained due to the short time between his arrival at the hospital, diagnosis and medical treatment.

Decide the conservative or surgical treatment in a precise way since this leads a patient to reduce comorbidities and permanent neurological damage.

\section{References}

1. Blackmore CC, Emerson SS, Mann FA, Koepsell TD (1999) Cervical spine imaging in patients with trauma: determination of fracture risk to optimize use. Radiology 211: 759-765. [Crossref]

2. National Spinal Cord Injury Association Resource Center (2013) www.sci-info-pages com/factsheets.html. Accessed 12 April 2013

3. Goldberg W, Mueller C, Panacek E, Tigges S, Hoffman JR, et al. (2001) Distribution and patterns of blunt traumatic cervical spine injury. Ann Emerg Med 38: 17-21. [Crossref]

4. Zaveri G, Das G (2017) Management of Sub-axial Cervical Spine Injuries. Indian J Orthop 51: 633-652. [Crossref]

5. Raniga SB, Menon V, Khamis S, Al Muzahmi, Butt S (2014) MDCTof acute subaxia cervical spine trauma: a mechanism-based approach, Insights Imaging 5:321-338.

6. Allen BL Jr, Fergusson RL, Lehmann TR, O'Brien RP (1982) A mechanistic classification of closed, indirect fractures and dislocations of the lower cervical spine. Spine 7: 1-27.

7. Marcon RM, Cristante AF, Teixeira WJ, Narasaki DK, Oliveira RP, et al. (2013) Fractures of the cervical spine. Clinics (Sao Paulo) 68: 1455-1461. [Crossref]

8. Koller H, Ames C, Mehdian H, Bartels R, et al. (2018) Characteristics of deformity surgery in patients with severe and rigid cervical kyphosis (CK): results of the CSRSEurope multi-centre study project. Eur Spine J DOI: 10.1007/s00586-018-5835-2. [Epub ahead of print] [Crossref]

9. Lingawi SS (2001) The naked facet sign. Radiology 219: 366-367. [Crossref]

10. Daffner SD, Daffner RH (2002) Computed tomography diagnosis of facet dislocations: the "hamburger bun" and "reverse hamburger bun" signs. J Emerg Med 23: 387-394. 
11. Palmieri F, Cassar-Pullicino VN, Dell'Atti C, Lalam RK, Tins BJ, et al. (2006) Uncovertebral joint injury in cervical facet dislocation: the headphones sign. Eur Radiol 16: 1312-1315.

12. Bracken MB, Shepard MJ, Holford TR, Leo-Summers L, Aldrich EF, et al. (1998) Methylprednisolone or tirilazad mesylate administration after acute spinal cord injury: 1-year follow up. Results of the third National Acute Spinal Cord Injury randomized controlled trial. J Neurosurg 89: 699-706.

13. Fehlings MG (2001) Spine Focus Panel. Summary statement: The use of methylprednisolone in acute spinal cord injury. Spine 26: S55.
14. Cotler HB, Miller LS, DeLucia FA, Cotler JM, Davne SH (1987) Closed reduction of cervical spine dislocations. Clin Orthop Relat Res 185-199. [Crossref]

15. Letaif OB, Damasceno ML, Cristante AF, Marcon RM, Iutaka AS, et al. (2010) Escolha da via ciru 'rgica para tratamento das fraturas cervicais. The choice of surgical approach for treatment of cervical fractures. Coluna/Columna 9: 358-362.

16. Schwab F, Ungar B, Blondel B, Buchowski J, Coe J, et al. (2012) Scoliosis Research Society-Schwab adult spinal deformity classification: a validation study. Spine 37: 1077-1082.

Copyright: (C2019 Olvera DQ. This is an open-access article distributed under the terms of the Creative Commons Attribution License, which permits unrestricted use, distribution, and reproduction in any medium, provided the original author and source are credited. 